\title{
Proceeding
}

9th INSHS International Christmas Sport Scientific Conference, 4-6 December 2014. International Network of Sport and Health Science. Szombathely, Hungary

\section{Sprint cycling performance and asymmetry}

\author{
INDREK RANNAMA , KRISTJAN PORT, BORIS BAZANOV, KIRSTI PEDAK \\ Institute of health Sciences and Sport, Tallinn University, Estonia
}

\begin{abstract}
Rannama, I., Port, K., Bazanov, B., \& Pedak, K. (2015). Sprint cycling performance and asymmetry. J. Hum. Sport Exerc., 9(Proc1), pp.S247-S258. The purpose of this study was to examine the asymmetries in cyclist's lower limbs strength and in the pedalling kinematics during a seated sprinting test and to identify the relationships between asymmetries and maximal cycling power. 16 competitive road cyclists $(20.6 \pm 3.7$ yrs., $181.5 \pm 5.0 \mathrm{~cm}, 74.8 \pm 7.0 \mathrm{~kg}$ ) performed $10 \mathrm{Sec}$ isokinetic maximum power test with cadence $120 \mathrm{RPM}$. The asymmetry of kinematic patterns of cyclist's upper and lower body during pedalling was registered. Separately isokinetic peak torque (PT) of main lover limbs joint were measured at angular speeds 60, 180 and $240 \mathrm{ls}$. The differences in kinematic patterns and isokinetic PT values between two limbs were analysed for descriptive and inferential statistics (relative share in \%, correlations and regression between asymmetry values and cycling power). Conclusion: The highest asymmetries were found in cyclist's upper body kinematics and at the same time the most symmetrical were knee extensors strength values, but both parameters were negatively and significantly correlated with the performance of sprint cycling. By combining the leg extensors muscular strength with asymmetry of knee extensors strength and trunk kinematics the explanatory power of multiple regressions increased markedly from 0.68 to 0.92 . Key words: PEAK TORQUE, ISOKINETIC DYNAMOMETRY, CYCLING KINEMATIC, STRENGTH ASYMMETRY.
\end{abstract}

\footnotetext{
Corresponding author. Institute of health Sciences and Sport, Tallinn University, Räägu 49. 11316 Tallinn. Estonia E-mail: rannama@tlu.ee 9th INSHS International Christmas Sport Scientific Conference, 4-6 December 2014. International Network of Sport and Health Science. Szombathely, Hungary. JOURNAL OF HUMAN SPORT \& EXERCISE ISSN 1988-5202

(C) Faculty of Education. University of Alicante doi:10.14198/jhse.2015.10.Proc1.12
} 


\section{INTRODUCTION}

Bicycling is a cyclic activity that requires in the competition situations a precise pedalling technique to maximize power application to the pedals with minimal energy cost. Although the cycling assumed to be an endurance sport, the ability to achieve a high maximum power during a short period of time is an important component of success in road cycling competitions (Ebert et al., 2006; Jeukendrup et al., 2000). Maximal cycling power output largely depends on external factors like bicycle set up (Gonzalez and Hull, 1989; To0, 1990; Rankin and Neptune, 2010; Vrints et al., 2011; Yoshihuku \& Herzog, 1990), pedalling cadence (Zoladz et al., 2000; Van Soest \& Casius, 2000; Dorel et al., 2005; Gardner et al., 2007; Busko, 2005), cyclists position on the bike (Bertucci et al., 2008). Also internal factors like lower limbs muscle strength (Alemdaroglu, 2012; Arslan, 2005; Rannama et al., 2013; Sanding et al., 2008; Smith, 1987), muscle coordination patterns (Blake et al., 2012) and fatigue (Martin \& Brown, 2009; O'Bryan et al. 2014) play important role for achieving high pedalling power. In most of studies, analysing maximal power output in cycling, assuming that cyclists are pedalling symmetrically (Carpes et al., 2010).

Number of studies have found a notable asymmetry in the bilateral kinetics patterns of the pedalling like a crank torque (Carpes et al., 2007; Bini \& Hume, 2014), different pedal force components (Daly \& Cavanagh, 1976; Sanderson et al., 1991; Smak et al., 1999) and pedal power output (Smak et al., 1999). Also some studies have found asymmetry in lower limbs joint kinematics and kinetics patterns (Smak et al., 1999; Edeline et al., 2004) and muscle activation (Carpes et al., 2011), but it is noted that pedalling kinetics asymmetry may not be related to bilateral differences in the muscle activation magnitude and its variability (Carpes et al., 2010). Edeline et al. (2004) demonstrated that even with a symmetrical pedal force production existing bilateral difference in the pedalling kinematics leads to the asymmetry in joint torques and muscle loads. This indicates that bilateral differences in the kinematics may be most sensitive measures of asymmetry.

It is reported that the pedalling cadence (Liu \& Jensen, 2012; Daly \& Cavanagh, 1976; Fregly \& Zajac, 1996; Smak et al., 1999), external workload (Edeline et al., 2004; Carpes et al., 2007b; Sanderson et al., 1991) and fatigue (Carpes et al., 2007a) have an influence on bilateral asymmetry. It seems that increase of the effort, due to higher power output or accumulated fatigue, improves the pedaling symmetry of the crank torque production (Carpes et al., 2007; Sanderson et al., 1991), but there are also opposing findings (Bini \& Hume, 2014). Carpes et al. (2010) conclude that asymmetries often disappear when cycling task is performed at maximal effort. The influence of pedaling speed to the asymmetry have individual variations within subjects in the cadence range between 60 and $90 \mathrm{rpm}$, but there is a trend of increasing asymmetry in higher and very low cadences (less than 60), especially in non-cyclists population (Liu \& Jensen, 2012; Smak et al., 1999).

The influence of the bilateral asymmetry on the cycling performance is not clear, but there are some findings of the relationship between the performance measures and the asymmetry from other cyclical and/or bilaterally equal motions. Yoshioka et al. (2010) examined the effect of $10 \%$ bilateral asymmetries of the muscle strength on countermovement jump performance by computer simulation and found only $0.7 \%$ difference in jump height. The experimental results of Bailey et al. (2013) indicate that force production asymmetry is negatively related to the bilateral vertical jumping performance and unlike the simulation study, in the real conditions the weaker leg may not be adequately compensated by the stronger leg.

In cyclical movements, where human body is connected with symmetrical equipment, it has been found that asymmetrical lower limb kinematics are negatively related with ergometer rowing performance (Buckeridge 
et al., 2012; Bull \& McGregor, 2000) and the kinematics of the rowers of higher competitive level (Buckeridge et al., 2012) and kayakers (Limonta et al., 2010) were bilaterally more symmetrical.

The literature on the relationships between various asymmetries and cycling sprinting performance is extremely limited. There is a lack of information how the asymmetries in the muscle strength are related with the movement kinematic and how the asymmetrical pedalling movements are affecting the power production during maximal cycling effort.

The purpose of this study was to examine the asymmetries in cyclist's lower limbs strength and in the pedalling kinematics during a seated sprinting test and to identify the relationships between asymmetries and maximal cycling power.

\section{MATERIAL AND METHODS}

\section{Participants}

The study participants were 16 competitive male road cyclists. The participants went through anthropometrical measurements (age $20.6 \pm 3.7 \mathrm{yrs}$., height $181.5 \pm 5.0 \mathrm{~cm}$ and body weight $74.8 \pm 7.0 \mathrm{~kg}$ ), completed a health screening questionnaire and signed an informed consent term in accordance with the principles of the Declaration of Helsinki. All cyclists were right-leg dominant, had at least 6 years focused cycling training and competition experience and last the season's cycling total distance was over the 15000 $\mathrm{km}$. The participants, had no general (done without bicycle) strength training history during the last 6 month and were free of injuries

\section{Instrumentation and procedures}

Experimental protocol consisted of 2 separate phases: cycling sprint power tests in 3 cadence conditions with 3D kinematic video recording of cyclist's movement and isokinetic strength testing of six lower limb muscle groups in 3 angular velocity conditions.

Both experimental phases were performed during the same day. Each subject completed at first cycling tests. After 20-30 minutes of free pedalling and passive recovery after which they went through the isokinetic strength testing. The experimental phase was performed at the end of cycling season during the cyclist's recovery period.

Cycling sprint power protocol. All tests were performed using the participants personal racing bike, which was mounted on a research grade cycling ergometer platform Cyclus 2 (Avantronic, Cyclus 2, Leipzig, Germany) that allows lateral incline of the bike that matches real life cycling. The warm-up consisted of 10 minutes of steady ride in power level of $100 \mathrm{~W}, 5$ minutes riding with progressively increasing power from $100 \mathrm{~W}$ to the level of $4 \mathrm{~W} / \mathrm{kg}, 2$ minutes in level of $4 \mathrm{~W} / \mathrm{kg}, 3$ minutes steady ride in power level of $100 \mathrm{~W}$ and one 6 seconds of isokinetic maximal sprint with cadence set in $100 \mathrm{rpm}$ followed 4 minutes recovery ride. After warm-up three separate bouts of sprint efforts with 4 minute rest periods in isokinetic mode were conducted. Four minute rest is shown to be sufficient for recovery (Billaut \& Giacomoni et al. 2003). For the testing the three target cadences were set of $100 \mathrm{rpm}, 120 \mathrm{rpm}$ and $140 \mathrm{rpm}$ accordingly, that covers the effectual cadence area for generating maximal power (Dorel et al. 2005; Gardner et al. 2007, Zoladz et al. 2000, Van Soest \& Casius 2000). All tests were conducted in sitting position hands on the drops. 
Pedalling kinematics. In order to measure the pedalling movement kinematic the modified marker set of a reduced number of external markers offered by Rodano, R. et al (1996) was used. Reflective markers were attached bilaterally on the cyclists anatomical reference points (Figure 1): ankle (lateral malleoli), knee (lateral epicondyle of the femur), hip (great trochanter), pelvis (iliac crest), shoulder (greater tubercle), elbow and wrist. Additional markers were placed on the lateral side of the pedal spindles and front and rear axles of bicycle. Diameter of the passive retro reflective markers was $12 \mathrm{~mm}$.

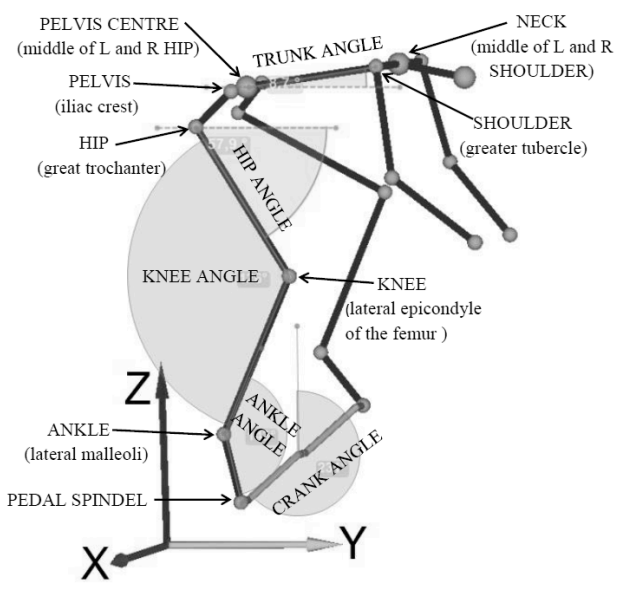

Figure 1. Anatomical reference point's and measured kinematical parameters.

All the cycling sprints were simultaneously recorded on a server using five Panasonic NV-GS230 DV cameras operating at $50 \mathrm{~Hz}$ and equipped with lights near to cameras lens. The cameras were mounted on the walls around the cyclists, zoomed so that the athlete was visible at maximal amount and connected with the FireWire cables to the computer. The movement space around the cycling ergometer was calibrated with $500 \times 1000 \times 1500 \mathrm{~mm}$ ( $X, Y$ and $Z$ axis respectively) calibration matric, so that line between front and rear axles of bicycle was in the same direction with the longitudinal axis of global frame.

Video files were synchronised by led light and software Gen-Loc using Kwon-3D biomechanical analysis software (Visol, Korea). 19-segment (Figure 1) model of the cyclists were semi-automatically digitized in each image of the trials. The digitized images were interpolated to $200 \mathrm{~Hz}$ using 3-order spline function and the 3-dimensional coordinates of the body landmarks were calculated using the direct linear transform (DLT) algorithm. Coordinate data were smoothed using a second-order Butterworth low pass digital filter with cut-off frequencies of $10 \mathrm{~Hz}$. Linear and angular positions, velocities and accelerations were computed from smoothed 3D coordinate data. Also secondary points were calculated with general mid-point method: Pelvic Centre (mid-point of Left \& Right Pelvis) and Neck (mid-point of Left \& Right Shoulder).

Kinematic data were interpolated with 3-order spline function from time scale to pedaling cycle scale $\left(360^{\circ}\right)$ - starting from 0 degree, when right crank is in upper position. 8 pedaling cycles between $1^{\text {st }}$ and $6^{\text {th }}$ second of sprint test were averaged to 1 cycle. Average cycle values of computed parameters were included to the future analysis.

Isokinetic strength protocol. A HUMAC 2009 NORM (Computer Sports Medicine, Inc. Stoughton, MA, USA) isokinetic dynamometer was used for the strength tests. The: ankle plantar flexors $(P F)$, ankle dorsal flexors $(D F)$, knee and hip extensors $(E X)$ and flexors $(F L)$ of both legs were tested accordingly. All tests procedures, dynamometer settings and securing of subjects to seat and measurement arms were carried 
out in accordance with the HUMAC NORM user manual. Ankle plantar and dorsi flexion tests were performed in the "Modified Seated" (supine) position, knee extension and flexion tests in seated position and hip extension and flexion tests in lying position.

The axis of rotation of the dynamometer lever arm was aligned with the anatomical axis of the joint being tested, as described in the HUMAC NORM test manual. The "gravity correction" features were used in all tests to avoid gravity effect of limb weight.

All joint movements were tested concentrically at velocities 60,180 and $240 \%$ s. At each test velocity, the subject performed 4 submaximal warm-up trials followed by 5 (60 and $180 \%$ s) or $15(240 \%$ s) maximal test trials after 30 seconds recovery. A recovery period of $60 \mathrm{~s}$ between test velocities, 5 minutes between body sides and 10 minutes between different joint actions was used.

\section{Measures}

Cycling power test. In the cycling power test significantly higher power were achieved in cadence of 120 rpm and resulting from this the performance and kinematics of $120 \mathrm{rpm}$ test were included to the future analysis. To eliminate the acceleration and fatiguing part from the 10 seconds the 5 seconds average relative power (POW5s) (W/kg) between 1-6 seconds was used as performance measure.

Pedalling kinematics. In present study only sagittal plane kinematic (around $\mathrm{X}$ axis) was analysed. The angles evaluated in this analysis were (Figure 1): trunk incline, hip (thigh incline), knee, ankle and bicycle crank angle. The extension and flexion angle $(A N)$, angular velocity $(A \vee e)$ and acceleration $(A A c)$ were computed to describe every angular parameter of the right $(R)$ and Left $(L)$ side. To describe pelvis motion the linear displacement in $Y$ and $Z$ direction and absolute velocity $(V e)$ and acceleration $(A c)$ of pelvis centre were computed. Also the range of motion (ROM) of AN, AVe and AAc were calculated.

Isokinetic strength. Measurement and initial analysis of isokinetic strength test variables were carried out in "HUMAC2009 NORM Application Program". The highest peak torque values of best repetition from all joint actions and testing speeds of right and left leg were analysed as muscle group strength (expressed in Nm). The measurement of peak torque has been shown to be accurate and highly reproducible (Kannus, 1994). All strength values were normalized with the body mass $(\mathrm{Nm} / \mathrm{kg})$ and the mean values of right and left leg was used in regression modelling.

Asymmetry. The absolute values of the asymmetry were included in present study. Absolute version of the ASI proposed by Vagenas \& Hoshizaki (1992) was used to assess the degree of asymmetry in PT values and was calculated using the following equation (1):

\section{Equation 1}

$$
A S I=\frac{|L-R|}{\max |L \cdot R|} * 100
$$

To account the time shifts and to compare the symmetries over the entire pedalling cycle and across different variables, the modified equation (2 and 3 ) of cycle asymmetry proposed by Nigg et al. (2013) was used: 
Equation 2

$A S I 360=\int_{c=c 1}^{c 360} \frac{2 *|R(t)-L(t)| \Delta c}{\operatorname{range}(R(c))+\operatorname{range}(L(c))} * 100$

where ASI360 is the asymmetry index, $R(c)$ is the value of a specific variable recorded for the right leg at the cycle position $\mathrm{c}$ and $\mathrm{L}(\mathrm{c})$ the value recorded for the left leg at the cycle position $\mathrm{c}, \mathrm{c} 1$ is the 1 degree position of $L$ or $R$ crank when pedaling cycle starts, and c360 is 360 degree position when pedaling cycle finished. The asymmetry is normalized by incorporating the range of the $R(c)$ and $L(c)$ variables, it makes possible to compare variables with different magnitudes as well as different units (Nigg et al. 2013).

The average ASI(\%) 360 were computed from AN, AVe and AAc values for hip, knee and ankle. For calculations of the asymmetry in the pelvis and trunk kinematics the values between $L$ and $R$ side pushing phases ( $1-180^{\circ}$ in pedalling cycle) were compared. The ASI 360 for the trunk were computed similarly to the legs. Pelvis ASI360 computed as mean of Pelvis Centre position ( $Y$ and $Z$ axis of sagittal plane), resultant linear velocity and acceleration ASI360.

Analysis

Statistical software SPSS version 21.0 (IBM company, New York) was used for data analysis. Descriptive data were expressed as mean \pm standard deviation (SD). All the data was tested for their normal distribution (Kolmogorov-Smirnov test). A Student's t-test for paired data was applied to compare asymmetry values between different joints and movements. Pearson product-moment correlation was used to examine the relationship between variables. Significance level for t-test and correlation tests was set at $p<0.05$. To examine the relationships between asymmetry variables (independent variables) and POW-5s (dependent variable), stepwise multiple linear regressions were performed. The entry significance level for independent variables was $P<0.05$, while the removal significance level was $P>0.10$.

\section{RESULTS}

The average absolute power of cycling sprint test was $1090 \pm 162 \mathrm{~W}$ (ranged from 777 to $1322 \mathrm{~W}$ ) and relative power (POW5s) was 14.5 \pm 1.5 (from 11.2 to $16.6 \mathrm{~W} / \mathrm{kg}$ ). The results of isokinetic PT and strength

Table 1. Descriptive data and correlations with POW-5s of relative isokinetic strength and strength asymmetry for the knee, hip and ankle joints at different velocities $(n=16)$

\begin{tabular}{|c|c|c|c|c|c|c|c|c|c|c|c|}
\hline $\begin{array}{l}\text { Peak Torque } \\
(\mathrm{Nm} / \mathrm{kg})\end{array}$ & Min & $\operatorname{Max}$ & Mean & Dev. & Correl. POW5s & $\begin{array}{l}\text { Peak Torque } \\
\text { Asymmetry }\end{array}$ & Min & $\operatorname{Max}$ & Mean & $\begin{array}{l}\text { Std. } \\
\text { Dev. }\end{array}$ & $\begin{array}{l}\text { Correl. } \\
\text { POW5s }\end{array}$ \\
\hline $\begin{array}{l}\text { Ankle } \\
\text { PF60PT }\end{array}$ & 1,06 & 1,72 & 1,43 & 0,22 & 0,38 & $\begin{array}{l}\text { Ankle } \\
\text { PF60ASI }\end{array}$ & 0,7 & 28,4 & 9,1 & 8,2 & 0,18 \\
\hline $\begin{array}{l}\text { Ankle } \\
\text { PF180PT }\end{array}$ & 0,66 & 1,14 & 0,91 & 0,16 & 0,07 & $\begin{array}{l}\text { Ankle } \\
\text { PF180ASI }\end{array}$ & 1,5 & 20,4 & 10,2 & 6,6 & 0,32 \\
\hline $\begin{array}{l}\text { kle } \\
\text { F240PT }\end{array}$ & 0,57 & 1,04 & 0,89 & 0 & 0,35 & $\begin{array}{l}\text { Ankle } \\
\text { PF240ASI }\end{array}$ & 1,2 & 37,0 & 12,7 & 91 & ,17 \\
\hline $\begin{array}{l}\text { nkle } \\
\text { F6OPT }\end{array}$ & 0,25 & 0,46 & 7 & & 0,20 & $\begin{array}{l}\text { Ankle } \\
\text { DF60ASI }\end{array}$ & 0,0 & 32,4 & 11,4 & 8,4 & 20 \\
\hline $\begin{array}{l}\text { Ikle } \\
\text { =180PT }\end{array}$ & 0,22 & 0,51 & 0,37 & 0,08 & 0,10 & $\begin{array}{l}\text { Ankle } \\
\text { DF180ASI }\end{array}$ & 0,0 & 29,0 & 13,3 & 11,1 & 0,42 \\
\hline
\end{tabular}
asymmetry, also the correlation coefficient with relative 5 seconds power are shown in Table 1. 


\begin{tabular}{|c|c|c|c|c|c|c|c|c|c|c|c|}
\hline $\begin{array}{l}\text { Ankle } \\
\text { DF240PT }\end{array}$ & 0,26 & 0,47 & 0,35 & 0,07 & 0,06 & $\begin{array}{l}\text { Ankle } \\
\text { DF240ASI }\end{array}$ & 0,0 & 36,6 & 11,1 & 12,4 & 0,24 \\
\hline $\begin{array}{l}\text { Knee } \\
\text { EX60PT }\end{array}$ & 2,20 & 3,95 & 2,99 & 0,41 & $0.65^{\star *}$ & $\begin{array}{l}\text { Knee } \\
\text { EX60ASI }\end{array}$ & 0,6 & 17,2 & 5,8 & 4,3 & $-0,04$ \\
\hline $\begin{array}{l}\text { Knee } \\
\text { EX180PT }\end{array}$ & 1,50 & 2,69 & 2,12 & 0,32 & $0.68^{* *}$ & $\begin{array}{l}\text { Knee } \\
\text { EX180ASI }\end{array}$ & 0,0 & 15,9 & 7,6 & 4,3 & $-0.50^{*}$ \\
\hline $\begin{array}{l}\text { Knee } \\
\text { EX240PT }\end{array}$ & 1,34 & 2,37 & 1,81 & 0,26 & $0.74^{* *}$ & $\begin{array}{l}\text { Knee } \\
\text { EX240ASI }\end{array}$ & 0,0 & 12,8 & 6,9 & 4,2 & $-0,25$ \\
\hline $\begin{array}{l}\text { Knee } \\
\text { FL60PT }\end{array}$ & 1,19 & 2,12 & 1,70 & 0,27 & $0.53^{*}$ & $\begin{array}{l}\text { Knee } \\
\text { FL60ASI }\end{array}$ & 0,0 & 18,3 & 8,2 & 6,1 & $-0,14$ \\
\hline $\begin{array}{l}\text { Knee } \\
\text { FL180PT }\end{array}$ & 0,97 & 1,61 & 1,26 & 0,18 & 0,39 & $\begin{array}{l}\text { Knee } \\
\text { FL180ASI }\end{array}$ & 2,7 & 27,9 & 9,9 & 7,4 & 0,08 \\
\hline $\begin{array}{l}\text { Knee } \\
\text { FL240PT }\end{array}$ & 0,84 & 1,42 & 1,12 & 0,16 & 0,44 & $\begin{array}{l}\text { Knee } \\
\text { FL240ASI }\end{array}$ & 0,0 & 31,3 & 9,2 & 8,5 & $-0,07$ \\
\hline Нip ЕX60РT & 2,87 & 6,03 & 4,17 & 0,68 & $0.64^{* *}$ & Hip EX60ASI & 0,0 & 17,9 & 7,5 & 5,3 & 0,43 \\
\hline $\begin{array}{l}\text { Hip } \\
\text { EX180PT }\end{array}$ & 2,13 & 4,14 & 3,27 & 0,46 & $0.74^{* *}$ & $\begin{array}{l}\text { Hip } \\
\text { EX180ASI }\end{array}$ & 1,8 & 24,6 & 9,5 & 7,6 & $-0,20$ \\
\hline $\begin{array}{l}\text { Hip } \\
\text { EX240PT }\end{array}$ & 2,33 & 3,44 & 2,93 & 0,34 & $0.74^{* *}$ & $\begin{array}{l}\text { Hip } \\
\text { EX240ASI }\end{array}$ & 0,0 & 20,9 & 8,5 & 6,1 & $-0,24$ \\
\hline Hip FL60PT & 1,03 & 2,76 & 2,23 & 0,42 & 0,23 & Hip FL60ASI & 0,0 & 15,6 & 7,0 & 4,4 & $-0,24$ \\
\hline $\begin{array}{l}\text { Hip } \\
\text { FL180PT }\end{array}$ & 1,13 & 2,20 & 1,73 & 0,27 & 0,14 & $\begin{array}{l}\text { Hip } \\
\text { FL180ASI }\end{array}$ & 0,7 & 20,9 & 9,9 & 5,8 & 0,09 \\
\hline $\begin{array}{l}\text { Hip } \\
\text { FL240PT }\end{array}$ & 1,08 & 2,06 & 1,52 & 0,25 & 0,34 & $\begin{array}{l}\text { Hip } \\
\text { FL240ASI }\end{array}$ & 0,8 & 29,6 & 8,5 & 8,4 & 0,22 \\
\hline
\end{tabular}

Note*. Correlation is significant at the 0.01 level (2-tailed) ${ }^{*}$. Correlation significant at the 0.05 level (2tailed).

Largest asymmetry was found from the strength of the muscle group crossing the ankle (significantly different $(p<0.05)$ between hip and knee asymmetry) and less asymmetrical were knee extensors. Number of significant relationships was found between the relative cycling sprint power and isokinetic strength components. Sprint power correlated significantly with the hip and knee extensors in all velocities and the knee flexors in velocities $60 \%$. It was also found that there is a negative correlation between the cyclist's power and knee extensors peak torque ASI.

Two 3-component multiple regression models with PT and PT ASI data were composed (Equations 3 and 4). Regression models including muscular strength and strength asymmetry can explain over the $80 \%$ of variation in short term cycling power. Also only the leg extensor muscle groups are involved in the models and knee extensors strength ASI affect negatively the performance. When only PT values were included in the models, then the prediction level was lower than $70 \%$ (R square 0.69 and 0.68 for models in equations 1 and 2 respectively) and with inclusion of knee PT ASI parameter the explanatory power of regression model increase significantly.

\section{Equation 3}

POW5s $=3.943+2.164 *$ KneeEX $240 P T+2.59 *$ HipEX $240 P T-0.134 *$ KneeEX $240 A S 1$

Equation 4

$\left(r^{2}=0.826\right)$ 
$P O W 5 s=5.616+3.676 *$ KneeEX $240 P T+2.133 *$ AnklePF $60 P T-0.106 *$ KneeEX $180 A S I$

The results of the kinematical ASI360 (Table 2) confirmed that the largest asymmetry does exist in upper body movement. There was no significant difference between pelvis and trunk ASI360 ( $p=0.5)$, but the upper body asymmetry values are significantly higher than legs ASI360 values $(p<0.05)$. Similar to PT ASI, were ankle muscles show largest asymmetry in the kinematics of the lower limb ankle ASI360 was higher $(p<0.05)$ than the knee and hip values. The knee and hip ASI360 did not differ significantly $(p=0.54)$.

The correlation analysis refers to significant negative relationships between POW5s and the upper body segments kinematical asymmetry however the inequality of legs kinematic did not correlate significantly with the sprinting power. ASI360 of the hip and knee are positively correlated and pelvis asymmetry correlates with the ankle and trunk asymmetry.

Table 2. Descriptive data of kinematical ASI360 and correlations between POW- 5 s and ASI360 values $(n=16)$

\begin{tabular}{cccccccccc}
\hline & \multicolumn{4}{c}{ Descriptive statistics } & \multicolumn{7}{c}{ Correlation } \\
\cline { 2 - 11 } $\begin{array}{c}\text { Kinematical } \\
\text { asymmetry }\end{array}$ & Min & Max & Mean & Std. Dev. & POW5s & ASI(\%)360 & ASI(\%)360 & ASI(\%)360 & ASI(\%)180 \\
\hline Ankle-ASI360 & 4,9 & 18,3 & 9,8 & 4,3 & $-0,31$ & & & & \\
Knee-ASI360 & 1,5 & 12,1 & 3,4 & 2,5 & 0,03 & 0,33 & & & \\
Hip-ASI360 & 1,4 & 7,6 & 3,7 & 1,6 & 0,12 & 0,36 & $0.68^{* *}$ & & \\
Trunk-ASI180 & 3,1 & 58,0 & 17,2 & 13,0 & $-0.65^{* *}$ & 0,26 & $-0,17$ & $-0,11$ & \\
Pelvis-ASI180 & 6,4 & 29,9 & 15,4 & 6,7 & $-0.63^{* *}$ & $0.531^{*}$ & $-0,07$ & 0,17 & $0.61^{*}$ \\
\hline
\end{tabular}

Note $^{* *}$ Correlation is significant at the 0.01 level (2-tailed). ${ }^{*}$. Correlation significant at the 0.05 level (2tailed).

Two components multiple regression model (Equation 5), when combining strength and kinematical asymmetries was stronger predictor of 5 seconds power production than looking separately the asymmetry of the knee extensors strength at $180 \mathrm{deg} / \mathrm{sec}$ or the trunk angular motion ASI360. Also the prediction power of ASI model (Equation 5) was in same level with prediction power of models where only PT values were included.

\section{Equation 5}

POW5s $=17.071-0.17 *$ TrunkASI360-0.072*KneeEX180ASI $\left(r^{2}=0.67\right)$

The highest prediction level was achieved by combining the PT and asymmetry patterns in the same regression model (Equation 6), then r-square rise to 92.

\section{Equation 6}

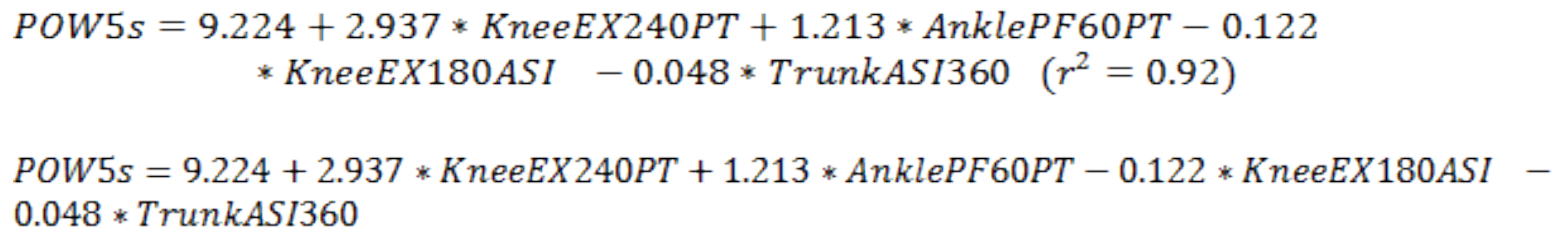




\section{DISCUSSION}

The aim of this study was to examine the asymmetries in cyclist's lower limbs strength, in the pedalling kinematics and the relationships between asymmetries and maximal cycling power. The subjects of present study demonstrated the highest asymmetry of upper body kinematics. In lower limbs were the most asymmetrical ankle joint torques and angular kinematics. Lower asymmetry of pedalling kinematics and PT values were observed from hip and knee parameters. Regarding the earlier findings that suggest enhanced symmetry in high intensity cycling (Carpes et al. 2010), shows the present study significant asymmetries in pedalling kinematics, especially in upper body and ankle kinematics. One reason of the notable asymmetry can be high pedalling cadence $(120 \mathrm{rpm})$ used in our study, because high cadence is declared to be the contributing factor of asymmetry (Liu \& Jensen, 2012; Smak et al., 1999). Relatively high cadence may also be the reason of large asymmetry in ankle motion. At cadence above $120 \mathrm{rpm}$ relative contribution of ankle plantar flexion in pedalling power production decrease (McDaniel et al. 2014) and cadence over $100 \mathrm{rpm}$ significantly increase EMG-activity of thigh muscles (Baum and Li 2003). Those results indicate compromised coordinative patterns for ankle joint that directs force to the pedal and this can increase differences between dominant and no dominant leg. Knee flexors and knee and hip extensors are main power generators in sprint cycling (Elmer et al. 2011; Martin \& Brown, 2009; McDaniel et al. 2014; O'Bryan et al. 2014) and are less affected by high cadence (McDaniel et al. 2014; Baum \& Li 2003). This can be reason of lower and related asymmetry in hip and knee joint kinematic and also lower asymmetries in PT values compared to ankle PT ASI.

No earlier data about upper body asymmetry in cycling are presented, but do exist findings from rowing where pelvis kinematics were influenced by asymmetrical movement of hips and knees (Buckeridge et al., 2012). In present study asymmetries of cyclist's pelvis and ankle were related, but no significant correlations were found with hip and knee movement asymmetry but at the same time existed relation between knee and hip asymmetry. Relation between ankle and pelvis asymmetrical movement need a future investigation.

The main finding of present study is remarkable negative relation between upper body asymmetry and maximum cycling power production. The asymmetry in trunk kinematic and knee EX strength at $180 \mathrm{deg} / \mathrm{s}$ with combination of knee EX and ankle PF PT can explain more than $90 \%$ from variability of sprint power production. The upper body asymmetry and its relation with cycling performance need a future investigation by including also pelvis asymmetry assessments in combination with trunk and pelvis region muscles performance.

One limitation of the present study was that force applied on the pedals and bilateral EMG of main leg muscles could not be measured. This would present whether differences in pedalling kinematics are related to differences in force production and muscular activity between legs.

\section{CONCLUSIONS}

The highest asymmetries were found in cyclist's upper body kinematics and at the same time the most symmetrical were knee extensors strength values, but both parameters were negatively and significantly correlated with the performance of sprint cycling. By combining the leg extensors muscular strength with asymmetry of knee extensors strength and trunk kinematics the explanatory power of multiple regressions increased markedly from 0.68 to 0.92 . 


\section{REFERENCES}

1. Alemdaroglu, U. (2012). The Relationship Between Muscle Strength, Anaerobic Performance, Agility, Sprint Ability and Vertical Jump Performance in Professional Basketball Players. J Hum Kinet, 31, pp.149-158

2. Arslan, C. (2005). Relationship between the 30-second Wingate test and characteristics of isometric and explosive leg strength in young subjects. J Strength Cond Res. 2005; 19(3), pp.658666.

3. Bailey, C., Sato, K., Alexander, R., Chiang, C., Stone, \& M.H. (2013). Isometric force production symmetry and jumping performance in college athletes. Journal of Trainology, 2(1), pp.1-5

4. Baum, BS., \& Li, L. (2013). Lower extremity muscle activities during cycling are influenced by load and frequency. J Electromyogr Kinesiol, 13, pp.181-190

5. Bertucci, W., Taiar, R., Toshev, Y., \& Letellier, T. (2008). Comparison of Biomechanical Criteria in Cycling Maximal Effort Test. Int J of Sports Sci Eng, 2(1), pp.36-46

6. Billaut, F., Giacomoni, M., \& Falgairette, G. (2003). Maximal intermittent cycling exercise: effects of recovery duration and gender. J Appl Physiol, 95(4), pp. 1632-1637

7. Bini, R.R., \& Hume, P.A. (2014). Assessment of Bilateral Asymmetry in Cycling Using a Commercial Instrumented Crank System and Instrumented Pedals. Int J Sports Physiol Perform, 9(5), pp.876-881

8. Buckeridge, E., Hislop, S., Bulla, A., \& McGregor, A. (2012). Kinematic Asymmetries of the Lower Limbs during Ergometer Rowing. Med Sci Sports Exerc, 44(11), pp.2147-2153

9. Bull, A.M.J., \& McGregor, A.H. (2000). Measuring spinal motion in rowers: the use of an electromagnetic device. Clin Biomech, 15(10), pp.772-776.

10. Busko, K. (2005). Power Output and Mechanical Efficiency of Human Muscle in Maximal Cycle Ergometer Efforts at Different Pedalling Rates. Biol Sport, 22(1), pp. 35-51

11. Carpes, F.P, Diefenthaeler, F., Bini, R.R., Stefanyshyn, D.J., Faria, I.E., \& Mota, C.B. (2011). Influence of leg preference on bilateral muscle activation during cycling. J Sports Sci, 29(2), pp.151-159

12. Carpes, F.P., Mota, C.B., \& Faria, I.E. (2010). On the bilateral asymmetry during running and cycling - A review considering leg preference. Phys Ther Sport, 11(4), pp.136-142.

13. Carpes, F. P., Rossato, M., Faria, I. E., \& Mota, C. B. (2007). Bilateral pedaling asymmetry during a simulated 40-km cycling time-trial. J Sport Med Phys Fit, 47(1), pp.51-57.

14. Daly D, Cavanagh PR. (1976). Asymmetry in bicycle ergometer pedalling. Med Sci Sports Exer, 8(3), pp.204-208.

15. Dorel, S., Hautier, C.A., Rambaud, O., Rouffet, D., Van Praagh, E., Lacour, J.R., \& Bourdin, M. (2005). Torque and power-velocity relationships in cycling: relevance to track sprint performance in world-class cyclists. Int J Sports Med, 26(9), pp.739-746

16. Ebert, T.R., Martin, D.T., Stephens, B., \& Withers, R.T. (2006). Power Output During a Professional Men's Road-Cycling Tour. Int J Sports Physiol Perf, 1(4), pp.324-335

17. Edeline, O., Polin, D., Tourny-Chollet, C., \& Weber, J. (2004). Effect of workload on bilateral pedaling kinematics in non-trained cyclists. J Hum Mov Stud, 46, pp.493-517.

18. Elmer, S.J., Barratt, P.R., Korff, T., \& Martin, J.C. (2011). Joint-Specific Power Production during Submaximal and Maximal Cycling. Med Sci Sports Exerc, 43(10), pp.1940-1947

19. Fregly, B.J., Zajac, F.E., \& Dairaghi, C.A. (1996). Crank inertial load has little effect on steady-state pedaling coordination. J Biomech, 29(12), pp.1559-1567. 
20. Gardner, A.S., Martin, J.C., Martin, D.T., Barras, M., \& Jenkins, D.G. (2007). Maximal torque- and power-pedaling rate relationships for elite sprint cyclists in laboratory and field tests. Eur $J$ Appl Physiol, 101(3) pp.287-292.

21. Gonzalez, H., \& Hull, M.L. (1989). Multivariable optimization of cycling biomechanics. J Biomech, 22(11-12) pp.1151-1161.

22. Jeukendrup, A.E., Craig, N.P., \& Hawley, J.A. (2000). The bioenergetics of World Class Cycling. J Sci Med Sport, 3(4) pp.414-33.

23. Kannus, P. (1994). Isokinetic evaluation of muscular performance: Implications for muscle testing and rehabilitation. Int J Sports Med, 15, pp.11-18.

24. Limonta, E., Squadrone, R., Rodano, R., Marzegan, A., Veicsteinas, A., \& Merati, G. (2010). Tridimensional kinematic analysis on a kayaking simulator: key factors to successful performance. Sport Sci Health, 6(1), pp.27-34.

25. Liu, T., \& Jensen, J.L. (2012). Age-Related Differences in Bilateral Asymmetry in Cycling Performance. Res Q Exercise Sport, 83(1), pp.114-119

26. Martin, J., \& Brown, N. (2009). Joint-specific power production and fatigue during maximal cycling. J Biomech, 42, pp.474-479.

27. McDaniel, J.N., Behjani, N.S., Elmer, S.J., Nicholas, Brown, N.A.T., \& Martin J.C. (2014). JointSpecific Power-Pedaling Rate Relationships During Maximal Cycling. J Appl Biomech, 30, pp.423430

28. Nigg, S., Vienneau, J., Maurer, C., \& Nigg, BM. (2013). Development of a symmetry index using discrete variables. Gait Posture, 38(1), pp.115-119.

29. O'Bryan, S.J., Brown, N.A., Billaut, F., \& Rouffet, D.M. (2014). Changes in muscle coordination and power output during sprint cycling. Neuroscience Letters, 25(576) pp.11-16.

30. Rankin, J.W., \& Neptune, R.R. (2010). The Influence of Seat Configuration on Maximal Average Crank Power During Pedaling: A Simulation Study. J Appl Biomech, 26(4), pp. 493-500.

31. Rannama, I., Bazanov, B., Baskin, K., Zilmer, K., Roosalu, M., \& Port, K. (2013). Isokinetic muscle strength and short term cycling power of road cyclists. J Hum Sport Exerc, 8(2): S19-S29

32. Rodano, R., Squadrone, R., \& Castagna, F. (1996). Simplified 3-D model for the calculation of body segment kinematic asymmetries in cycling; 14th INTERNATIONAL SYMPOSIUM ON BIOMECHANICS IN SPORT, pp.213-216

33. Sanderson, D.J, Hennig, E.M, Black, A.H. (1991). The influence of cadence and power output on the biomechanics of force application during steady-rate cycling in competitive and recreational cyclists. Journal of Sports Sciences, 9, pp.191-203.

34. Sandig, D., Mühlenhoff, S., Wirth, K., \& Schmidtbleicher, D. (2008). Relation between maximal power output during isokinetic workout on a cycling ergometer and maximal strength. Isokinet Exerc Sci, 16(3), pp.189.

35. Smak, W., Neptune, R.R., \& Hull, M.L. (1999). The influence of pedaling rate on bilateral asymmetry in cycling. J Biomech, 32(9), pp.899-906.

36. Smith, D.J. (1987). The relationship between anaerobic power and isokinetic torque outputs. Can J Sport Sci, 12(1), pp.3-5.

37. Too, D. (1990). Biomechanics of cycling and factors affecting performance. Sports Med., 10, pp.286-302.

38. Vagenas, G., \& Hoshizaki, B.A. (1992). Multivariable Analysis of Lower Extremity Kinematic Asymmetry in Running. International J Sport Biomec, 8(1), pp.11-29.

39. Van Soest, O., \& Casius, L.J. (2000). Which factors determine the optimal pedaling rate in sprint cycling? Med Sci Sports Exerc, 32(11), pp.1927-1934. 
40. Vrints, J., Koninckx, E., Van Leemputte, M., \& Jonkers, I. (2011). The Effect of Saddle Position on Maximal Power Output and Moment Generating Capacity of Lower Limb Muscles During Isokinetic Cycling. J Appl Biomec, 27(1), pp.1-7.

41. Yoshihuku, Y., \& Herzog, W. (1990). Optimal design parameters of the bicycle-rider System for maximal power output. J Biomech, 23, pp.1069-1079.

42. Yoshioka, S., Nagano, A., Hay, D.C., \& Fukashiro, S. (2010). The effect of bilateral asymmetry of muscle strength on jumping height of the countermovement jump: A computer simulation study. $J$ Sports Sci, 28(2), pp.209-218.

43. Zoladz, J.A., Rademaker, A.C., \& Sargeant, A.J. (2000). Human muscle power generating capability during cycling at different pedalling rates. Exp Physiol, 85(1), pp.117-24. 